\title{
ПРАВОВЫЕ ОСНОВАНИЯ И ВИДЫ НАСЛЕДОВАНИЯ В ГРАЖДАНСКОМ ЗАКОНОДАТЕЛЬСТВЕ РОССИИ
}

\begin{abstract}
Аннотация: В данной статье рассматриваются правовые основания и виды наследования в гражданском праве РФ с учетом новейших положений российского законодательства. Цель исследования - рассмотреть правовые категории в сфере оснований наследования по российскому наследственному праву. Предложен авторский подход к вопросам наследования. Предлагаемый новый подход к пониманию оснований наследования позволит решить некоторые частные вопросы наследственного преемства различных категорий наследников, в том числе за счет обоснования иелесообразности распространения на них тех или иных условий наследования по завещчанию, по закону. В ходе исследования применялась совокупность общенаучных и частно-научных методов, что позволило спрогнозировать определеннье тенденции в развитии института наследственного права и выработать ряд научно-обоснованных рекомендаций и предложений. Под правовыми основаниями наследования в гражданском законодательстве России понимается завещание и закон, что не соответствует действительности. Предложено дифференичиовать основания наследования и виды наследования, на базе этого построить логичный понятийный аппарат, который был бы использован в теории гражданского права и в законодательстве. В статье дается авторская классификация оснований наследования.
\end{abstract}

Ключевые слова: Наследник, наследодатель, наследование, наследственная трансмиссия, наследственная субституция, право представления, выморочное имущество, юридический факт, правопреемство, правоспособность.

Abstract: This article examines the legal grounds and types of inheritance in Russia's civil law, considering the most recent positions of the Russian legislation. The goal of this research is to review the legal categories with regards to bases to inheritance according to the law of inheritance of the Russian Federation. The author suggests an original approach towards the questions of inheritance. The proposed new approach towards understanding the grounds for inheritance will allow solving certain questions of hereditary succession of various categories of heirs, including through justification of purposefulness of the coverage of particular conditions of inheritance for the heirs by the will or law. During the course of this research the author applied a combination of general scientific and private scientific methods, which allowed forecasting certain trends in development of the institution of inheritance law, as well as formulating a number of scientifically substantiated recommendations and propositions. This work suggests to differentiate the grounds for inheritance and types of inheritance, and based on this fact establish a logical conceptual framework, which would be used in the theory of civil law and legislation. The author's classification of the grounds for inheritance is being presented in the article.

Keywords: Hereditary substitution, Right of representation, Escheated property, Juridical fact, Legal succession, Legal competence, Hereditary transmission, Inheritance, Inheritor, Heir.

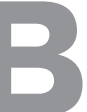

системе гражданского права основания наследования всегда занимали центральное место, так как именно на юридической модели правовых оснований наследования базируется порядок, условия и последствия призвания наследников к наследованию. Однако вопрос что понимать под правовыми основаниями наследования является дискуссионным.

Многие исследователи отмечали, что применение юридических терминов «наследование по завещанию» и «наследование по закону» как оснований наследования является устоявшимся в российском законодательстве и теории гражданского права (О.В. Мананников ${ }^{1}$,

${ }^{1}$ Мананников О.В. Наследственное право России. М., 2002. С.65.
К.П. Победоносцев ${ }^{2}$ и др.). Так согласно статье 1111 Гражданского кодекса РФ основаниями наследования являются завещание и закон: «наследование осуществляется по завещанию и по закону», насколько точны данные понятия? Можно сделать логичный вывод, что завещание и закон привычно называют основаниями наследования, однако они лишь обозначают порядок развития наследственных правоотношений. Следует согласиться с выводами Садикова О.Н.․,

\footnotetext{
2 Победоносиев К.П. Курс гражданского права. Часть вторая: права семейственные, наследственные и завещательные. М., 2003. C. 233 .

${ }^{3}$ Комментарий к Гражданскому кодексу Российской Федерации, части первой (постатейный) / отв. ред. О.Н. Садиков. М., 2005. C.91.
} 
Треушникова М.К. ${ }^{4}$, что и название статьи 1111 ГК РФ — «Основания наследования» неудачно.

Эта нечеткость терминологии не только породила трудности в научной литературе, но и имеет негативные последствия в наследственном законодательстве РФ и правоприменительной практике. Однако Ю.А.Тимонина и Т.А. Фесечко придерживаются противоположной позиции полагая, что «модель правовых оснований наследования, закрепленная в ст. 1111 ГК РФ вполне себя оправдывает»5.

Тем не менее, цивилисты отмечают, что несмотря на множество нововведений в Гражданский кодекс РФ проблема неточности понятия «основания наследования» приводит к путанице, например в п.3 ст.1158 Гражданского кодекса РФ сказано: «...если наследник призывается к наследованию одновременно по нескольким основанием (по завещанию и по закону или в порядке наследственной трансмиссии и в результате открытия наследства и тому подобное), он вправе отказаться от наследства, причитающегося ему по одному из этих оснований, по нескольким из них или по всем основаниям».

Возникает вопрос, почему законодатель, указывая на основания наследования упоминает наследственную трансмиссию и открытие наследства, ведь в законодательстве однозначно в статье 1111 ГК РФ в качестве оснований наследования указаны завещание и закон? Наряду с этим Гражданский кодекс РФ указывает в качестве оснований наследования и иные обстоятельства (открытие наследства, переход права на принятие наследства, направленный отказ от наследства, наследование в качестве подназначенного наследника и т.п.), которые по мнению Е.А. Суханова необходимо рассматривать как частные случаи проявления одного из двух общих оснований наследования ${ }^{6}$ Р Рассматривая данный вопрос некоторые юристы практики не поддерживают данную точку зрения, определяя например, подназначение наследника не как частный случай проявления одного из оснований наследования, а как самостоятельный вид наследования ${ }^{7}$.

Наследственная трансмиссия как самостоятельное основание наследования рассматривалось мно-

\footnotetext{
4 Ученые юристы МГУ о современном праве / под ред. М.К. Треушникова. М., 2005. С.55.

5 Тимонина Ю.В., Фесечко Т.А. Комментарий к части третьей Гражданского кодекса Российской Федерации. - М.,2002. - С.11.

${ }^{6}$ Гражданское право. Т.1 / отв. ред. Е.А. Суханов. М., 2005. С.180.

${ }^{7}$ Великоклад Т. П. Развитие положений о наследовании по завещанию в законодательстве Российской Федерации: автореферат дис. ... канд. юрид. наук. М., 2007. С.14.
}

гими учеными юристами при этом указывалось, что условия наступления наследственной трансмиссии, имеют немаловажное значение, позволяют ее определить как один из видов наследования и констатировать, что наследственная трансмиссия занимает самостоятельное место в системе приобретения наследства и не пересекается с принятием наследства по праву представления, по праву подназначения наследника и в порядке приращения наследственных долей.

В российском наследственном законодательстве, как и в законодательстве стран Западной Европы и США существует два варианта регламентации правоотношений, которые возникают в связи с приобретением наследства. Главное различие наследственных правоотношений заключается в наличие или отсутствии волеизъявления наследодателя в отношении своего имущества на случай смерти. «Аналогичным образом, в России существует два способа принятия наследства - по завещанию и по закону и в каждом случае правопреемство регулируется определенным образом в соответствии с законодательством» ${ }^{8}$.

Серебровский В.И. справедливо отмечал, что действительным основанием наследования является не закон и не завещание написанное наследодателем, а некоторые юридические факты, предусмотренные законодательством, например, такие как смерть наследодателя, усыновление (удочерение) им наследника, брак с наследодателем, родство наследодателя с наследником ${ }^{9}$. В науке кроме приведенных юридических фактов принято выделять юридические состояния ${ }^{10}$. Между тем, к правоотношениям относятся не все юридические состояния, например, завещатель и его племянник могут не состоять ни в каких правоотношениях, но при определенных условиях состояние родства может стать необходимым юридическим фактом, который приведет к возникновению наследственных правоотношений.

В классификации юридических фактов юридическим состояниям отводят самостоятельное место, классификация проводится в зависимости от завершенности их проявления и выражения, при этом главным отличием юридических состояний является однократность совершенных действий или

\footnotetext{
8 Ярошенко К.Б. Новое законодательство о наследовании // Хозяйство и право. 2010. №3. С.34.

${ }_{9}^{9}$ Серебровский В.И. Избранные труды. М., 1997. С.232.

${ }^{10}$ Стальгевич A.K. Некоторые вопросы теории социалистических правовых отношений // Советское государство и право. 1957. N 2. C. 31 .
} 
событий ${ }^{11}$. По мнению Красавчикова О.А. ${ }^{12}$ под основаниями возникновения, изменения, прекращения наследственного правоотношения следует понимать юридические факты, которые в зависимости от наличия или отсутствия волевого момента могут быть разделены на две группы:

1. события (смерть наследодателя);

2. действия (принятие наследства).

При наследовании по завещанию по мнению Великоклад Т.П..$^{13}$ имеют значение такие юридические факты как состояния - родство наследника с наследодателем, супружество наследодателя и наследника. Учитывая значение завещания, необходимо иметь в виду, что наследование - это производный способ возникновения права собственности, при котором правопреемство возникает благодаря наличию определенных юридических фактов. Имущество завещателя может стать имуществом наследников только в результате его смерти, то есть при наличие юридического факта с которым гражданское законодательство связывает прекращение гражданской правоспособности физического лица, так как юридический факт, прекращающий правоспособность, является и юридическим фактом, дающим начало наследованию. Таким образом, особое свойство наследования заключается в том, что оно возникает после прекращения правоспособности гражданина ${ }^{14}$.

При наследовании по закону следует учитывать такие юридические факты как состояния родство наследника с наследодателем, супружество наследодателя и наследника, усыновление (удочерение). ${ }^{15}$ Соглашаясь с данным мнением Черепахин Б.Б. дифференцировал юридические факты в зависимости от способов вступления в наследование. Эйдинова Э.Б. подчеркивает что, своеобразие оснований возникновения наследственных правоотношений заключается в том, что они всегда выступают как сложный фактический состав, а не как единичный юридический факт ${ }^{16}$.

Совокупность юридических фактов, которые приводят к возникновению наследственных правоотношений следует разделить на две основные группы, к одной группе относятся юридические факты, являющиеся предпосылками возникновения права наследования, они должны иметь место ко времени открытия наследства. Состав наследников прежде всего зависит от этих фактов. В первой группе юридических фактов можно выделить факты наследования по завещанию и факты наследования по закону. Ко второй группе юридических фактов, ведущих к возникновению наследственного правового отношения, относятся: смерть гражданина (событие); объявление безвестно отсутствующего гражданина умершим в судебном порядке (действие).

Можно сделать логичный вывод, что многие цивилисты предпринимали попытки отграничить основания наследования от видов и подвидов наследования. Применяя данный подход в теории гражданского права можно создать логичную схему в которой основания наследования это определенные юридические факты, виды наследования это способ принятия наследования, при этом нужно учесть, что наследственная трансмиссия и наследственная субституция занимают особое самостоятельное место среди видов наследования, к подвидам наследования следует отнести принятие выморочного имущества государством, наследование денежных средств на счетах в банках.

Таким образом, основаниями наследования является сложный состав юридических фактов, а завещание и закон виды наследования, к видам наследования относятся также наследственная трансмиссия, наследственная субституция и наследование по праву представления.

Кроме того в наследственном законодательстве и в науке гражданского права используются подвиды наследования к которым относится, например, наследование денежных средств на счетах в банках. Наглядно это можно изобразить в приведенной схеме:

\footnotetext{
${ }^{11}$ Иоффе О.С. Правоотношение по советскому гражданскому праву. Избранные труды по гражданскому праву. М., 2000. С. 229

${ }^{12}$ Красавчиков О.А. Юридические факты в советском гражданском праве. М., 1958. С. 82.

${ }^{13}$ Великоклад Т. П. Развитие положений о наследовании по завещанию в законодательстве Российской Федерации: автореферат дис. ... канд. юрид. наук. M., 2007. C.14.

${ }^{14}$ Комментарий к Гражданскому кодексу РФ, части третьей / под. ред. М.М. Абовой, А.Г. Богуславского. M., 2004. C.226.
}

${ }^{15}$ Великоклад Т. П. Развитие положений о наследовании по завещанию в законодательстве Российской Федерации: автореферат дис. ... канд. юрид. наук. М., 2007. С.14.

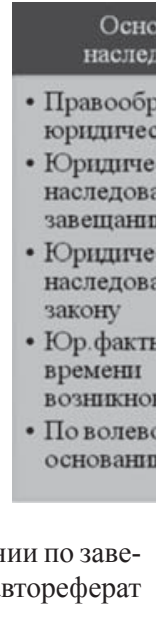

Основания

ледования пия ге факты кие факты пи по ките факты ия по по

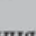
osy

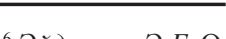
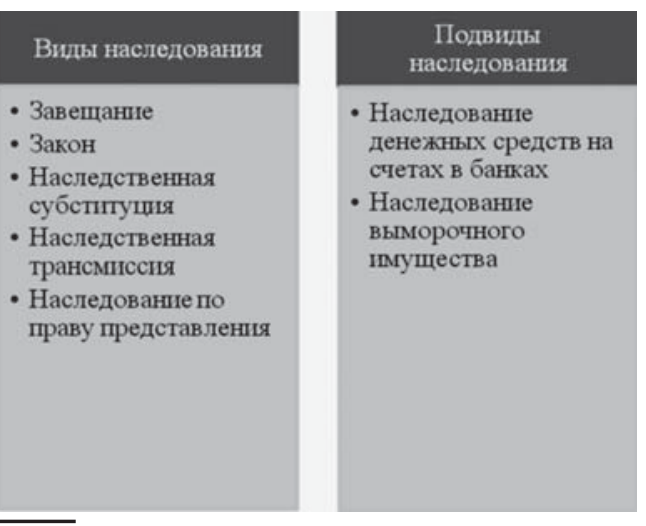

Эйинова Э.Б. Осуществление наследственных прав и защита их судом и нотариатом: диссертация кандидата юридических наук. М., 1972. С. 8. 
DOI: $10.7256 / 1811-9018.2016 .8 .12858$

При цитировании этой статьи сноска на doi обязательна

Право и политика $8(200) \cdot 2016$

Среди рассмотренных юридических фактов для возникновения наследственного правопреемства единственным и достаточным является факт смерти наследодателя (объявление наследодателя умершим), наступление других юридических фактов или состояний ко времени открытия наследства может быть необязательным. При их отсутствии наследство, как выморочное в порядке универсального правопреемства перейдет к государству.

В теории гражданского права необходимо использовать следующую классификацию оснований наследования:

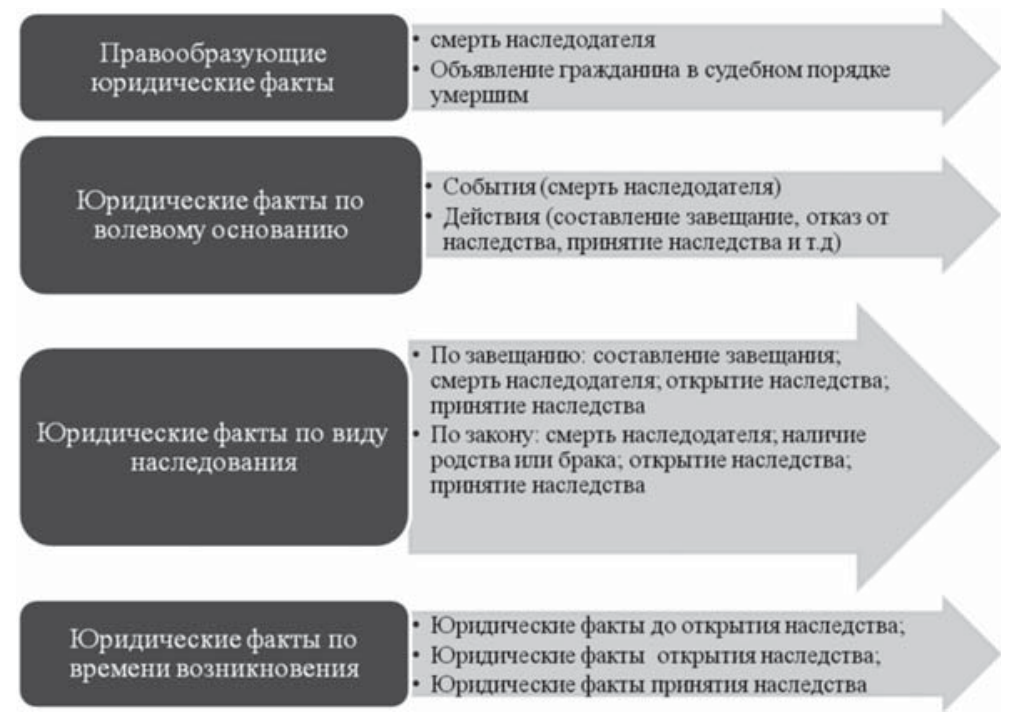

\section{Библиография:}

1. Мананников О.В. Наследственное право России. - М.: Статут, 2004.

2. Победоносцев К.П. Курс гражданского права. Часть вторая: права семейственные, наследственные и завещательные. - М.: Статут, 2013.

3. Ярошенко К.Б. Новое законодательство о наследовании // Хозяйство и право. - 2010. - №3. - С.34.

4. Серебровский В.И. Избранные труды. - М.: Юрист, 1997.

5. Комментарий к Гражданскому кодексу Российской Федерации, части первой (постатейный) / отв. ред. О.Н. Садиков. - М.: Норма, 2005.

6. Ученые юристы МГУ о современном праве / под ред. М.К. Треушникова. - М.: Городец, 2005.

7. Комментарий к Гражданскому кодексу РФ, части третьей / под. ред. М.М. Абовой, А.Г. Богуславского. - М.: Инфра-М, 2004.

8. Красавчиков О.А. Юридические факты в советском гражданском праве. - М.: Высшая школа, 1958.

9. Великоклад Т. П. Развитие положений о наследовании по завещанию в законодательстве Российской Федерации: автореферат дис. ... канд. юрид. наук. - М., 2007.

10. Гражданское право. Т.1 / отв. ред. Е.А. Суханов. - М.: Норма, 2005.

11. Стальгевич А.К. Некоторые вопросы теории социалистических правовых отношений // Советское государство и право. - 1957. - № 2. - С. 31

12. Иоффе О.С. Правоотношение по советскому гражданскому праву. Избранные труды по гражданскому праву. - М.: Статут, 2000.

13. Толстой Ю.К. К теории правоотношения. - Л., 1959.

14. Тимонина Ю.В., Фесечко Т.А. Комментарий к части третьей Гражданского кодекса Российской Федерации. - М.: Юрист, 2002.

15. Эйдинова Э.Б. Осуществление наследственных прав и защита их судом и нотариатом: диссертация кандидата юридических наук. - М.: Норма, 1972.

16. Тарасова И.Н. Допустимость совместной формы завещания в российском гражданском праве // Право и политика. 2013. - 7. - С. 876-879. DOI: 10.7256/1811-9018.2013.7.8888.

17. Шовкринский А.Ю. Виды оснований для исключений из нормы об исчерпании внутренних средств правовой защиты, признанных в международном праве // NB: Вопросы права и политики. - 2014. - 5. - C. 69-91. DOI: 10.7256/23059699.2014.5.11876. URL: http://www.e-notabene.ru/lr/article_11876.html

18. Михайлова Е.В. Проблемы наследования прав участия в коммерческих организациях // Право и политика. - 2014. 5. - C. 719-727. DOI: 10.7256/1811-9018.2014.5.11741.

19. Гаврилов В.Н. Роль нотариуса при оформлении наследства // NB: Вопросы права и политики. — 2013. - № 4. - С.286300. DOI: 10.7256/2305-9699.2013.4.667. URL: http://e-notabene.ru/lr/article 667.html 
DOI: $10.7256 / 1811-9018.2016 .8 .12858$

При цитировании этой статьи сноска на doi обязательна

Правоведение

20. Леонова О.А., Будылин С.Л.. Резидентность физического лица по налоговому законодательству Германии и России // Налоги и налогообложение. - 2013. - № 6. - С. 104-107. DOI: 10.7256/1812-8688.2013.6.892

21. Тарасова И.Н. Допустимость совместной формы завещания в российском гражданском праве // Право и политика. 2013. - 7. - C. 876 - 879. DOI: 10.7256/1811-9018.2013.7.8888.

\section{References (transliterated):}

1. Manannikov O.V. Nasledstvennoe pravo Rossii. - M.: Statut, 2004.

2. Pobedonostsev K.P. Kurs grazhdanskogo prava. Chast' vtoraya: prava semeistvennye, nasledstvennye i zaveshchatel'nye. M.: Statut, 2013

3. Yaroshenko K.B. Novoe zakonodatel'stvo o nasledovanii // Khozyaistvo i pravo. - 2010. - №3. - S.34.

4. Serebrovskii V.I. Izbrannye trudy. - M.: Yurist, 1997.

5. Kommentarii k Grazhdanskomu kodeksu RF, chasti tret'ei / pod. red. M.M. Abovoi, A.G. Boguslavskogo. - M.: Infra-M, 2004.

6. Krasavchikov O.A. Yuridicheskie fakty v sovetskom grazhdanskom prave. - M.: Vysshaya shkola, 1958.

7. Velikoklad T. P. Razvitie polozhenii o nasledovanii po zaveshchaniyu v zakonodatel'stve Rossiiskoi Federatsii: avtoreferat dis. ... kand. yurid. nauk. - M., 2007.

8. Stal'gevich A.K. Nekotorye voprosy teorii sotsialisticheskikh pravovykh otnoshenii // Sovetskoe gosudarstvo i pravo. - 1957. - № 2. - S. 31 .

9. Ioffe O.S. Pravootnoshenie po sovetskomu grazhdanskomu pravu. Izbrannye trudy po grazhdanskomu pravu. - M.: Statut, 2000.

10. Tolstoi Yu.K. K teorii pravootnosheniya. - L., 1959.

11. Timonina Yu.V., Fesechko T.A. Kommentarii k chasti tret'ei Grazhdanskogo kodeksa Rossiiskoi Federatsii. - M.: Yurist, 2002.

12. Eidinova E.B. Osushchestvlenie nasledstvennykh prav i zashchita ikh sudom i notariatom: dissertatsiya kandidata yuridicheskikh nauk. - M.: Norma, 1972.

13. Tarasova I.N. Dopustimost' sovmestnoi formy zaveshchaniya v rossiiskom grazhdanskom prave // Pravo i politika. - 2013. 7. - C. 876-879. DOI: 10.7256/1811-9018.2013.7.8888.

14. Shovkrinskii A.Yu. Vidy osnovanii dlya isklyuchenii iz normy ob ischerpanii vnutrennikh sredstv pravovoi zashchity, priznannykh v mezhdunarodnom prave // NB: Voprosy prava i politiki. - 2014. - 5. - C. 69-91. DOI: 10.7256/2305-9699.2014.5.11876. URL: http://www.e-notabene.ru/lr/article_11876.html

15. Mikhailova E.V. Problemy nasledovaniya prav uchastiya v kommercheskikh organizatsiyakh // Pravo i politika. $-2014 .-5$. - C. 719-727. DOI: 10.7256/1811-9018.2014.5.11741.

16. Gavrilov V.N. Rol' notariusa pri oformlenii nasledstva // NB: Voprosy prava i politiki. — 2013. - № 4. - S.286-300. DOI: 10.7256/2305-9699.2013.4.667. URL: http://e-notabene.ru/lr/article_667.html

17. Leonova O.A., Budylin S.L.. Rezidentnost' fizicheskogo litsa po nalogovomu zakonodatel'stvu Germanii i Rossii // Nalogi i nalogooblozhenie. - 2013. - № 6. - S. 104-107. DOI: 10.7256/1812-8688.2013.6.892

18. Tarasova I.N. Dopustimost' sovmestnoi formy zaveshchaniya v rossiiskom grazhdanskom prave // Pravo i politika. - 2013. 7. - C. 876 - 879. DOI: 10.7256/1811-9018.2013.7.8888. 